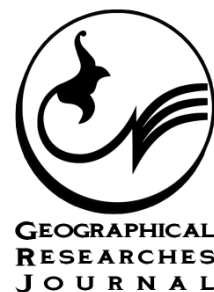

\title{
Effect of the Place Identity Components on Place Attachment; Study of the Tabriz Historic Bazaar
}

\section{A R T I C L E I N F O}

\section{Article Type}

Original Research

\section{Authors}

Haghparast F. ${ }^{* 1} P h D$,

Asefi M. ${ }^{1} \mathrm{PhD}$,

Abizadeh E. ${ }^{1} M A$
How to cite this article

Haghparast F, Asefi M, Abizadeh

E. Effect of the Place Identity Co-

mponents on Place Attachment; Study of the Tabriz Historic Bazaar. Geographical Researches. 2019;34(3):303-312.
${ }^{1}$ Department of Architecture, Faculty of Architecture and Urbanism, Tabriz Islamic Art University, Tabriz, Iran

\section{*Correspondence}

Address: Faculty of architecture and urbanisem, Saat (Clock) Sq, Maghsodiyeh St, Mosala St, Tabriz. Iran

Phone: +98 (41) 35541090

Fax: +98 (41) 35539200

f.haghparast@tabriziau.ac.ir

\section{Article History}

Received: December 24, 2018

Accepted: July 12, 2019

ePublished: October 2, 2019

\section{A B S T R A C T}

Introduction and Background Iranian historic bazaars are the dynamic hotspots of the cities that have a vital role in shaping a sense of place attachment. Among these, Tabriz Historic Bazaar with its unique characteristics is very important. The present study aims at determining the place identity components and their effects on the place attachment among business owners at Tabriz Historic Bazaar.

Methodology The present correlational study was conducted among business owners at Tabriz Historic Bazaar in 2018 and 374 people were selected randomly for the research. For data collection, questionnaire with 36 components in 6 dimensions were used. Data analysis was carried out using Spearman Correlation and Multiple Regression tests.

Findings Results demonstrated that the coefficient of the most important place identity components with place attachment was significant at $\mathrm{p}<0.01$ and criteria of memorability, satisfaction as well as introduction and identification had maximum coefficient with place attachment with the coefficients of $0.541,0.480$ and 0.412 , respectively. Components of memorability with the beta coefficient of 0.314 , satisfaction with the beta coefficient of 0.241 as well as introduction and identification with the beta coefficient of 0.140 had respectively the highest regression effects on the place attachment.

Conclusion Considering the role of place identity components and the extent of their influence on the sense of place attachment along with the efforts to preserve them in Tabriz Bazaar would help the survival of this valuable architectural heritage, while the quality of Bazaar will be enhanced as well. Keywords Tabriz Historic Bazaar; Place Identity; Business Owners of Bazaar; Place Attachment

\section{I T A T I O N L I N KS}

[Abasi Z, et al; 2015] An analysis of environmental concepts affecting the meaning of component in the traditional Iranian market, case study: Comparative comparison of Kashan traditional market and safavid commercial complex of Kashan; [Ahmadi F, et al; 2014] Factors influencing a sense of belonging in the regeneration of noghan neighborhood in the residential fabric near the Imam Reza Shrine; [Arbab P, et al; 2016] Explanation of the key criteria of the process of Place-Identity formation in new urban development; [Low \& Altman; 1992] Place attachment; [Canter; 1977] The psychology of place; [Droseltis \& Vignoles; 2010] Towards an integrative model of place identification: Dimensionality and predictors of intrapersonal-level place preferences; [Falahat; 2006] Concept of sense of place and its constituent factors; [Giddens; 1991] Modernity and self - Identity: Self and society in the late modern age; [Gustafson; 2001] Meaning of place: Very day experience and theorethical conceptualization; [Habibi, et al; 2018] Explaining the sense of belonging to place and identity in urban spaces with an emphasis on traditional markets; [Habibi; 2014] Tabriz Grand Bazaar; [Heidari, et al; 2014] Analysis of the physical sense of place in the traditional houses and modern residential apartments; [ICHHTO; 2009] Executive summary Tabriz historical bazaar complex; [Javan Foruzandeh \& Motallebi; 2011] The concept of place attachment and its elements; [Kalali \& Modiri; 2012] Explanation of the role of meaning component in the process of creating the sense of place; [Kashi \& Bonyadi; 2013] Stating the model of identity of place-sense of place and surveying its constituents case study: Pedestrian passage of Shahre Rey; [Mohammad Moradi \& Bahmani Oskooei; 2010] Traditional market: Crisising contemporary urbanism; [Navari, et al; 2008] Tabriz Markets Bridge; [Proshansky; 1978] The city and self-Identity; [Proshansky, et al; 1983] Place-Identity: Physical world socialization of the self; [Relph; 2008] Place and placelessness; [Shamai; 1991] Sense of place: An empirical measurement; [Soini, et al; 2012] Residents' sense of place and landscape perceptions at the rural-urban interface; [Steele; 1981] The sense of place; [Tan, et al; 2018] Sense of place and sustainability of intangible cultural heritage-The case of George Town and Melaka; [Tavakolianferdosieh, et al; 2016] Redesigning bazaar based on its collective memories formation and retention case study: Bazaar Khan, city of Yazd; [Tuan; 1974] Classics in human geography revisited: Topophilia; [Zangiabadi, et al; 2012] Strategic planning, to organize traditional Iranian markets a case study: The traditional market of Tabriz. 
[Heidari et al, آنها و تعلّق روحى و روانى افرد به مكان مى شكود

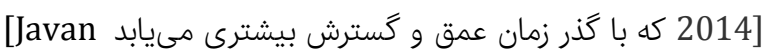
Foruzandeh \& Motallebi, 2011; Relph, 2008; Tuan,1974] امروزه روند گسستت مكان شتاب بيشترى گرفته و

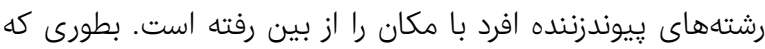

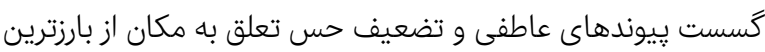
مشكلات معمارى و شهرسازى است. بازارها در حكم اسناد هويتبخش به يك يك جامعه شهرى هستنات

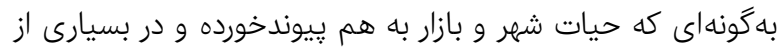

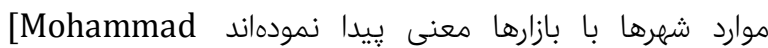
Moradi \& Bahmani Oskooei, 2010] بازارهاى تاريخى ايران با مجموعهاى وسيع از كاربرىها بهاعنوان

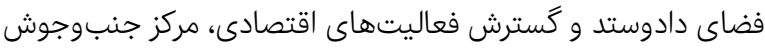

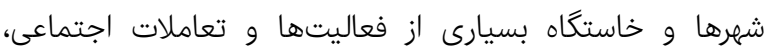

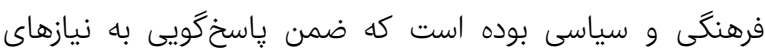

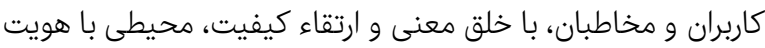

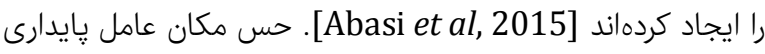

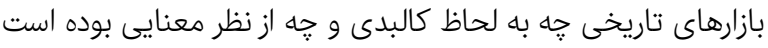

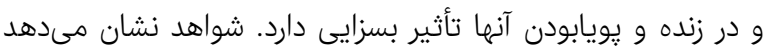
كه حس مكان در بسيارى از مواقع در ميان كسبه بازار بار با ارتقا بانه

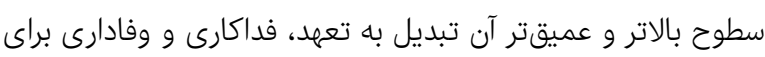

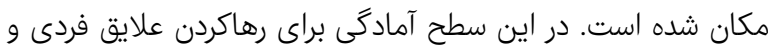

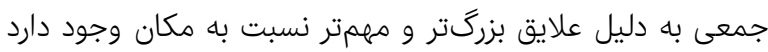

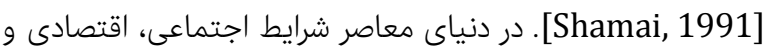

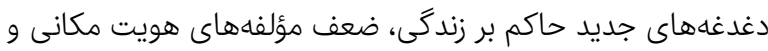

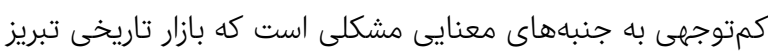

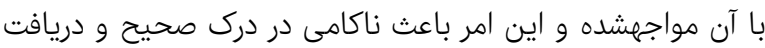

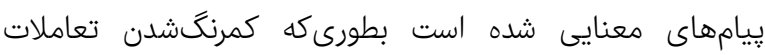

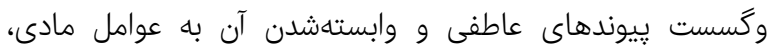
تضعيف حس تعلق مكانى را به همراه داشته است. بهاعبارتى ديكر

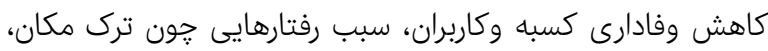
عدم تعهد اجتماعى، خالىشدن بازار و فرسايش كالبدى و عملكردى

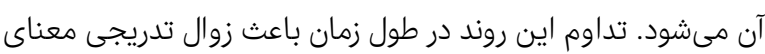

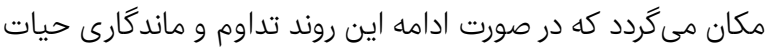

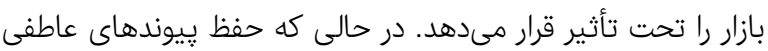

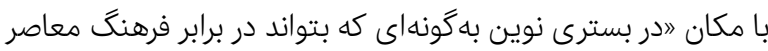

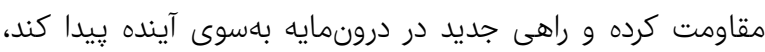

ضرورى است" [Tavakolianferdosieh et al, 2016] از آنجا كه از ديرباز حس مكان و سطوح مختلف آن از جمله حس

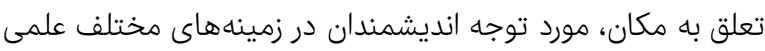

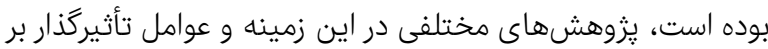

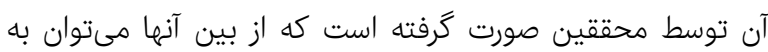

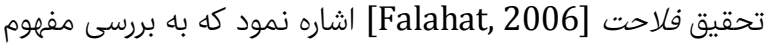
حس مكان و عوامل شكلدهنده و سطوح مختلف آن، از ديدًا لههاى
تأثير مؤلفههاى هويت مكان بر حسر حس تعلق به

\section{مكان؛ مطالعه بازار تاريخى تبريز}

فرزين حقيرست

كروه معمارى، دانشكده معمارى و شهرسازى، دانشگاه هنر اسلامى تبريز، تبريز،

PhD مازيار آصفى

كروه معمارى، دانشكده معمارى و شهرسازى، دانشگاه هنر اسلامى تبريز، تبريز،

ايران

MA الناز ابقزانه

كَره معمارى، دانشكده معمارى و شهرسازى، دانشگاه هنر اسلامى تبريز، تبريز، ايران

جكيده اهداف و زمينهها: بازارهاى تاريخى ايران بهعنوان كانون هويتبخش و و بوياى

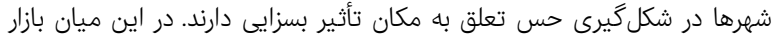

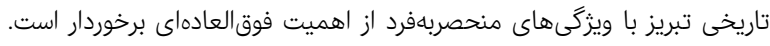

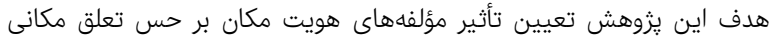

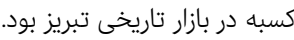

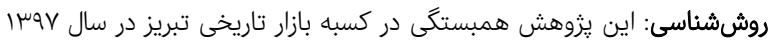

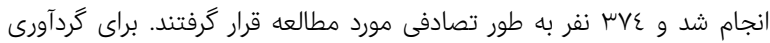

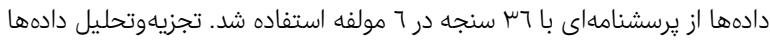

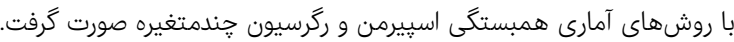

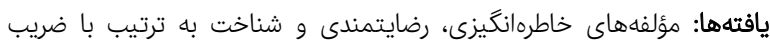

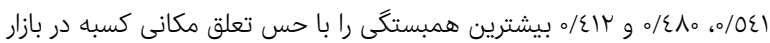

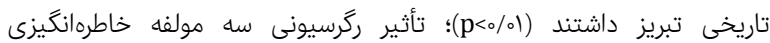

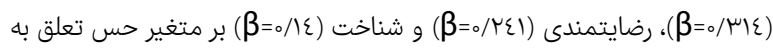

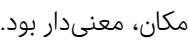

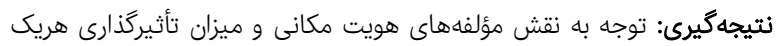

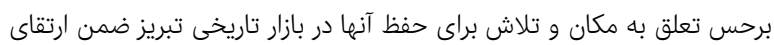

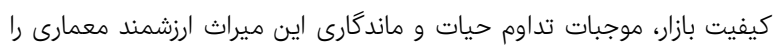

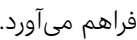
كليدوازمها: بازار تاريخى تبريز، هويت مكان، كسبه بازار، حس تعلق مكانى

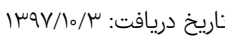

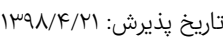

"نويسنده مسئول: f.haghparast@tabriziau.ac.ir

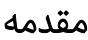

يكى از مهمترين شاخصههاى ارتباط انسان با مكان، حس تعلق به

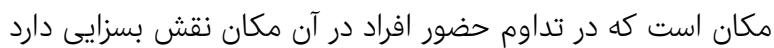

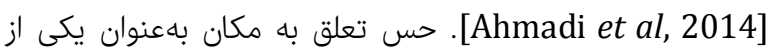

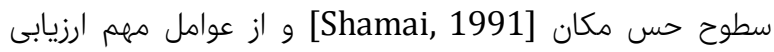

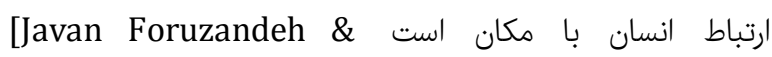
Sotallebi, 2011]

حسى و رفتارى ويزه براى افراد مىشود [Falahat, 2006].

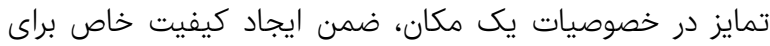
افراد، باعث شكل گَيرى بايههاى ارتباطى افراد با مكان، تعامل ميان ميان 


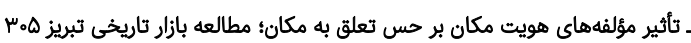

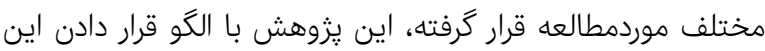

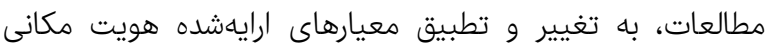

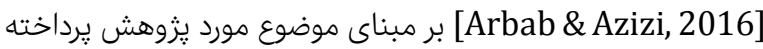

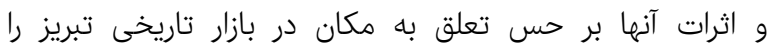

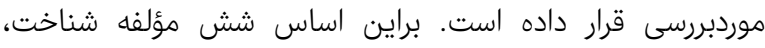

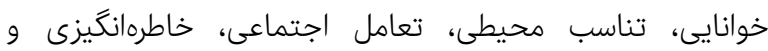

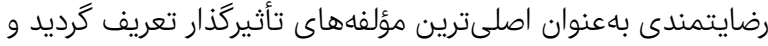

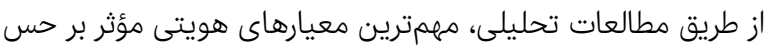

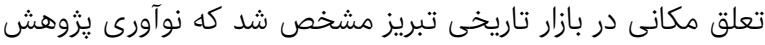
حاضر است. ديدكاههاى مختلفى در ارتباط با هويت مكان ارايه شده است كه

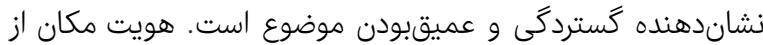

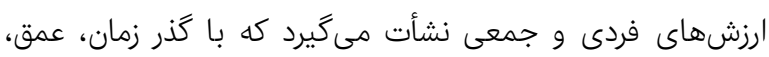

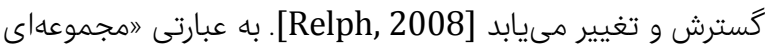

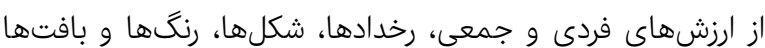

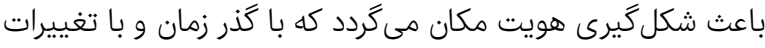

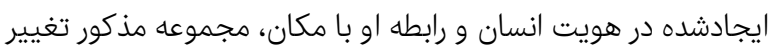

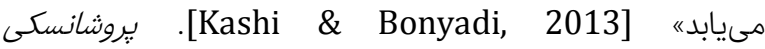

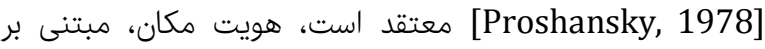
كذشته محيطى با يشتصحنه ادراكى بهواسطه شناخت و ادراك

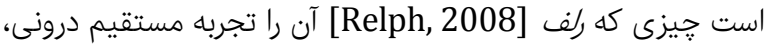

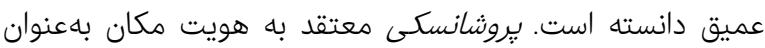
زيرساختارى ادراكى از هويت شخصى و مبتنى بر ذهنيت فرد نسبت

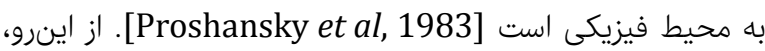

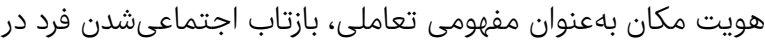

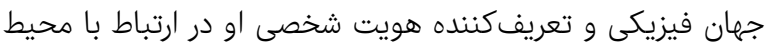
فيزيكى خاصى است [Arbab \& Azizi, 2016]. كيدنز

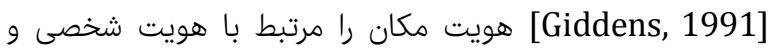

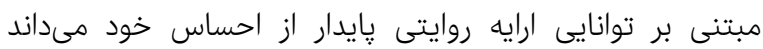

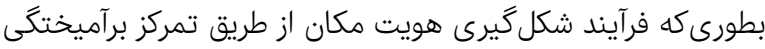

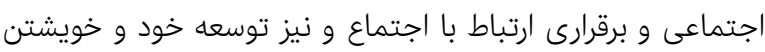

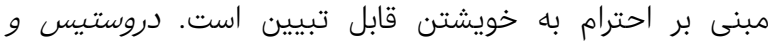

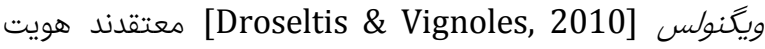
مكان محصول پاسخكويى مكان به نيازها و انكيزههاى ساكنان و

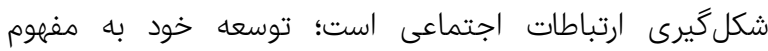

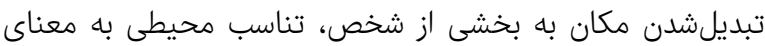

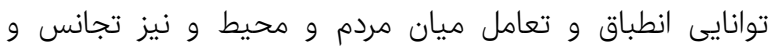

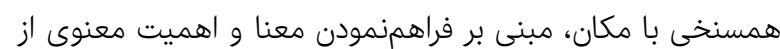
سوى محيط براى شخص، سه مؤلفه كليدى در زمينه هويت مكان مبن منان

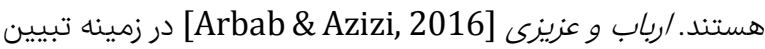

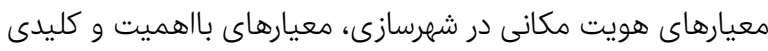
شناخت مبنى بر آكاهى و ادراك نسبت به محيط درئ فيزيكى و ابعادي مياد اجتماعى، خوانايى و تشخيص مبنى بر وجود كيفيات و ارتباطات قابلدرك، متنوع، برجسته و خاص، رضايتمندى مبنى بر احساس
مختلف يرداخته است. در دستهبندى ارايه شده توسط فلاحت عوامل تأثيرگذار بر حس مكان در دو دسته اصلى فعاليتها و معانى درانى

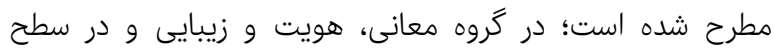
فعاليتها، تعاملات اجتماعى، حس اجتماع و رضايتمندى رونى قرار

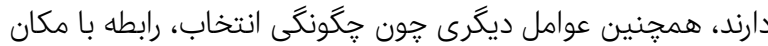

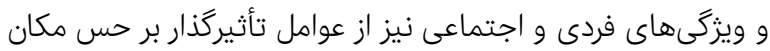
هستند. جوانفروزنده و مطلبى \& Motallebi, 2011] عوامل تشكيلدهنده آن را مورد بررسى قرار دادند و حس مس تعلق به

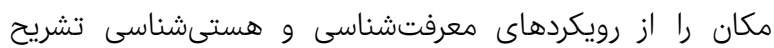

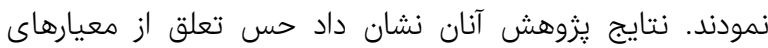

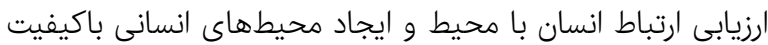

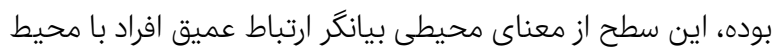

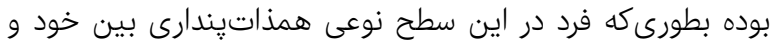

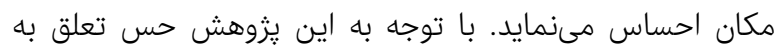
مكان منطبق بر مدل شكل مانيرى معنا در محيط برآيند تعامل فرده

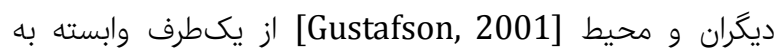

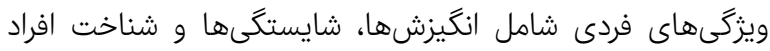

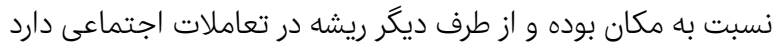
كه منبعث از نيازهاى انسانى تعلق است. احمدى و ودمان هماران

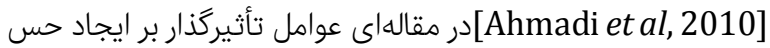
تعلق به مكان را ناشى از فرد و محيط دانستهاند بطورىكه عوامل

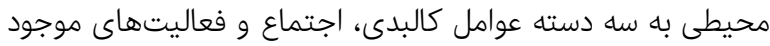
و عوامل فردى به دو دسته ويزگىهاى فردى و تصورات ذهنى إسى

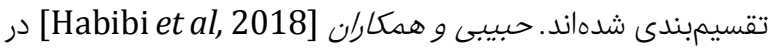
يزوهشى كه با هدف تبيين حس تعلق به مكان در فضاهاى شهرى

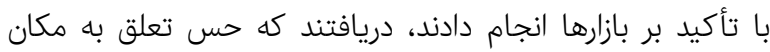
عاملى مهم و موثر در شكلگيرى يايههاى ارتباطى افراد و محيط لهيط

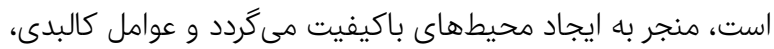

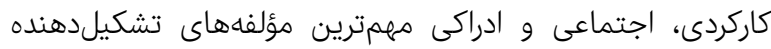
حس تعلق به مكان هستند. تان و همكاران [Tan et al, 2018] نيز در يزوهشى كه بامنظور بررسى حس مكان و پايدارى ميراث

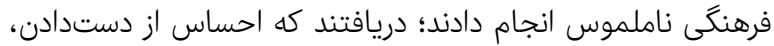

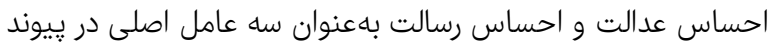
شخص به مكان نقش دارد كه باعث مشاركت جامعه در حفظ ميراث

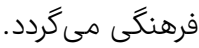

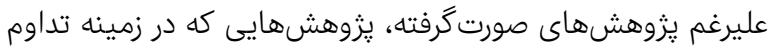
حيات بازار تاريخى تبريز با تأكيد بر تعيين تأثير مؤلفههاى كليديدى صوني

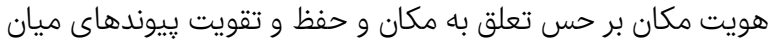

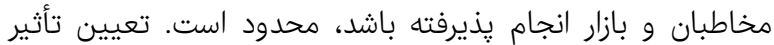

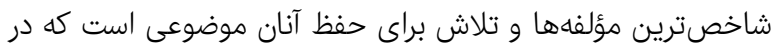

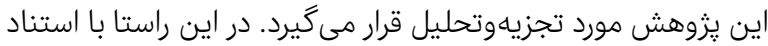

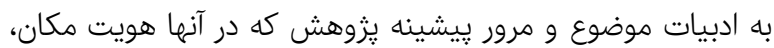
حس مكان و تعلق به مكان باصورت مجزا در زمينهها و ابعاد 
مكان)؛ ارتباط اقتصادى (ايجاد رابطه بهواسطه مالكيت)؛ ارتباط

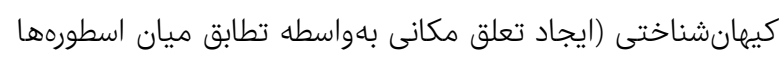

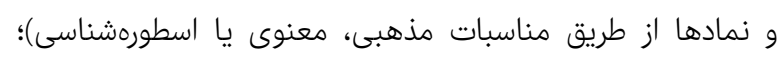

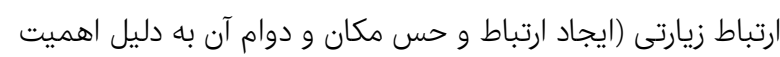

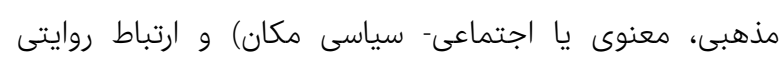

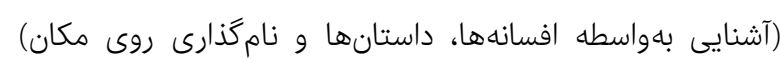

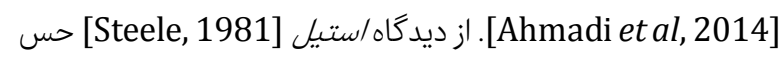
تعلق به مكان بريايه حس مكان، فراتر از آكاهى از استقاه استقرار در يك

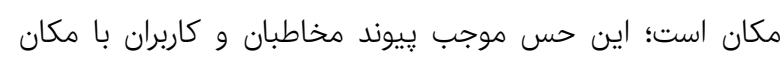

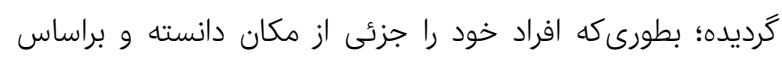

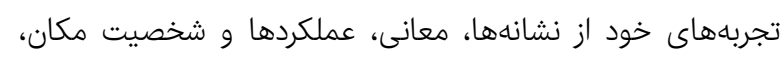

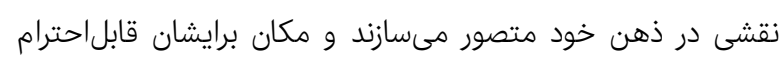

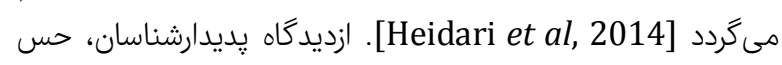

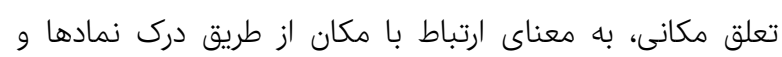

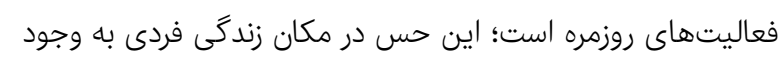

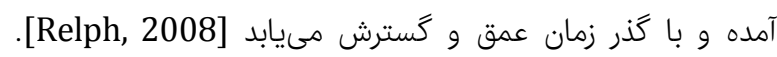

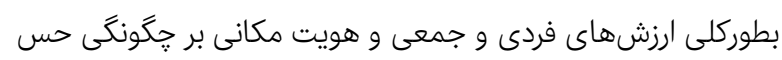

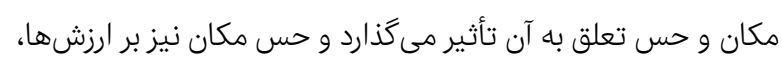

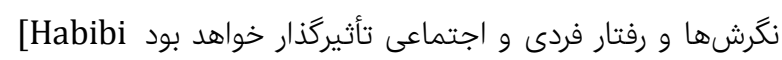
.et al, 2018; Canter, 1977]

\section{روششناسى}

يزووهش حاضر به لحاظ هدف كاربردى و از جهت ماهيت و روش

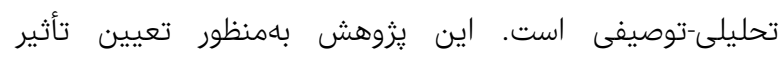

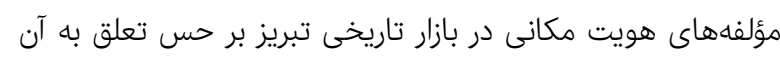

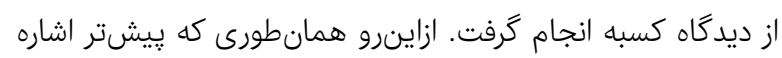

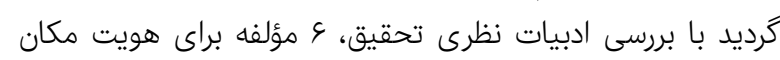

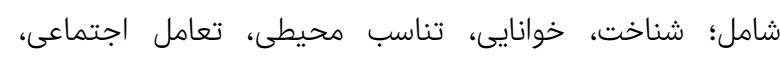

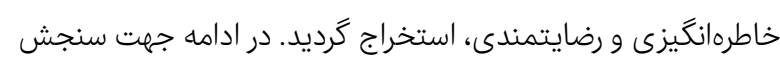

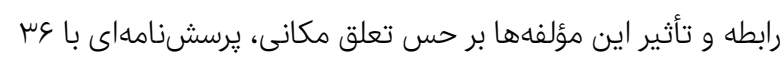

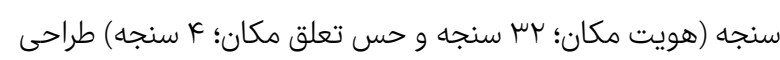

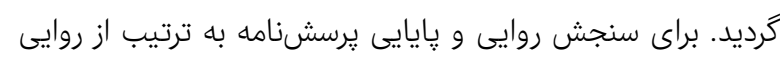

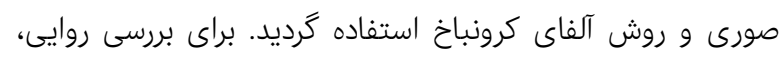

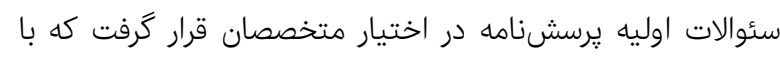

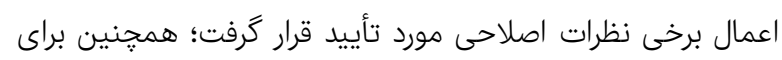

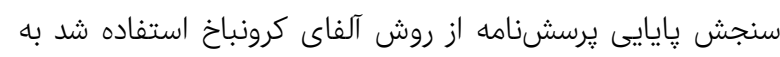

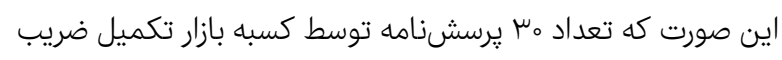

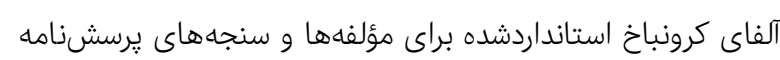

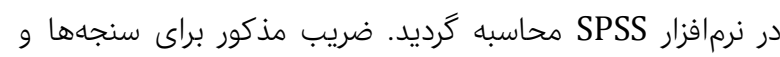

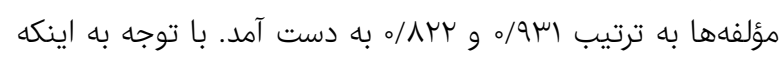

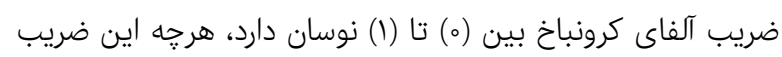

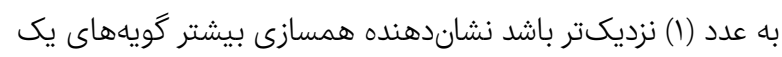

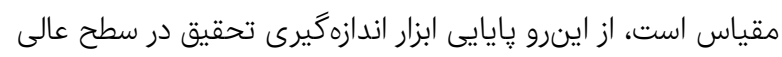

$$
\text { تأييد شد (جدول اسن (). }
$$

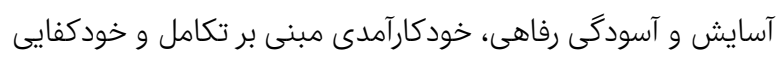

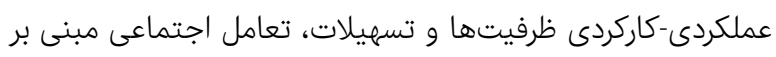

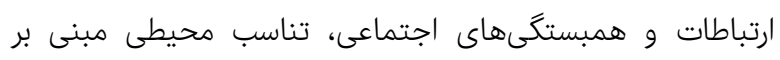

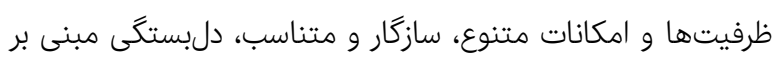

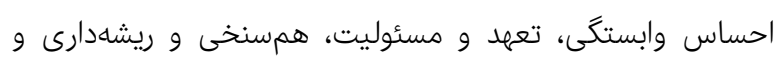

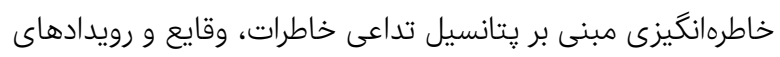

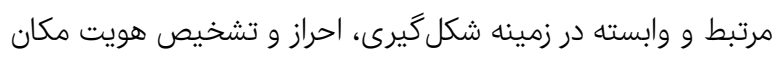
معرفى نمودهاند

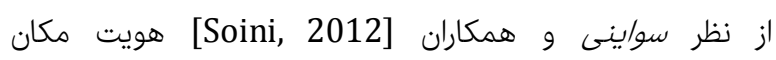

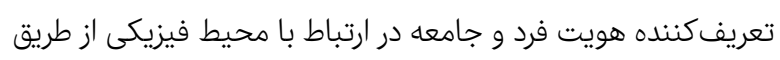

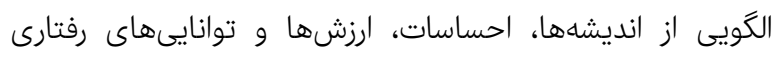

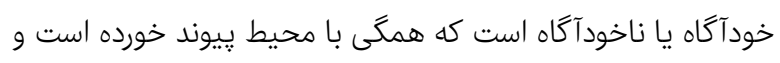

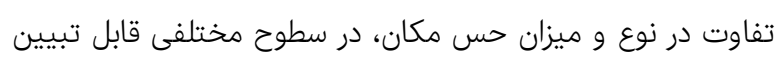

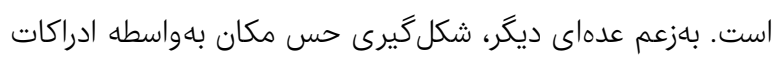

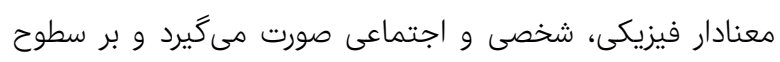

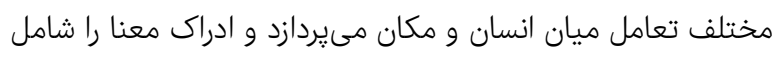

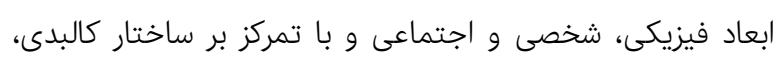

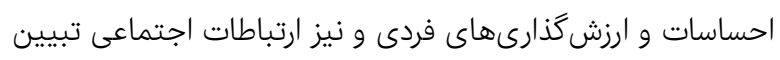

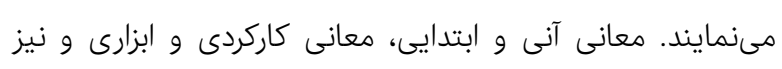

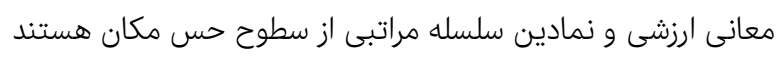

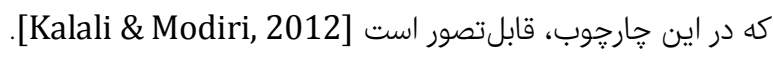

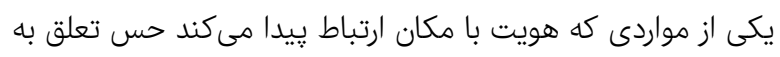

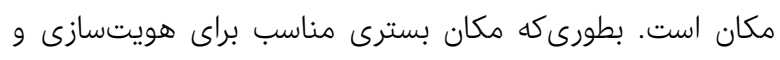

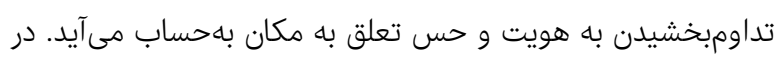

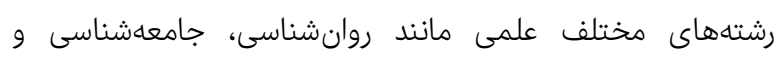

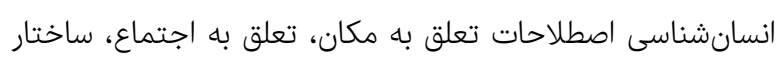

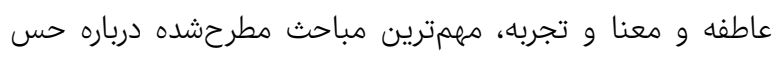

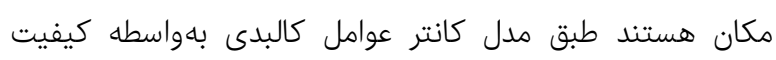

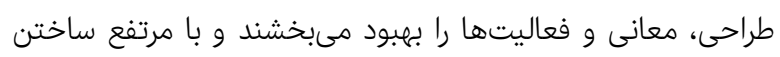

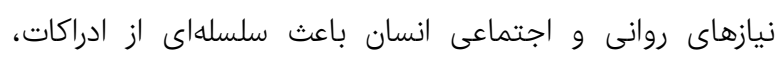

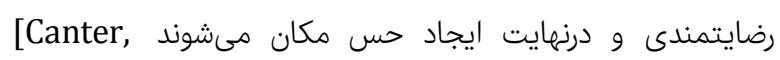

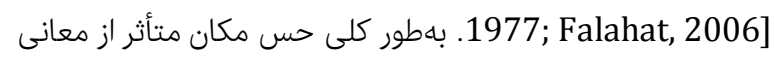

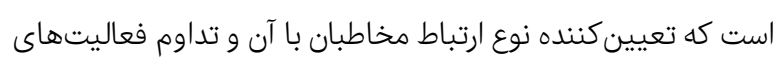

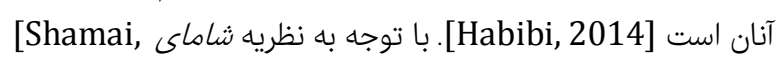

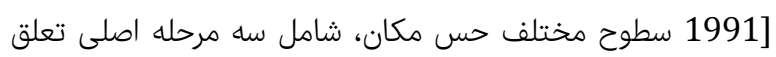

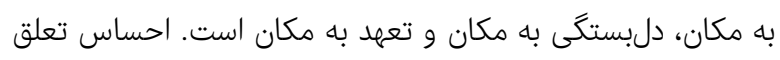

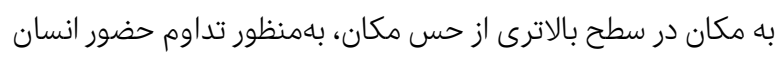

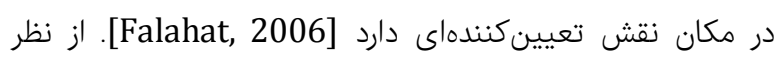
آلتمن و لو [Altman \& Low,1992] شش نوع نوع رابطه نمادين

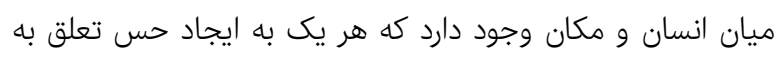

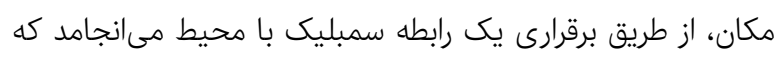

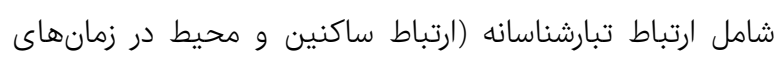

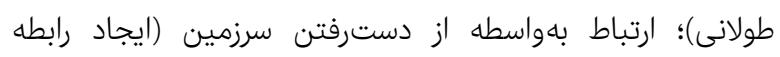
بهواسطه از دستدادن و تجديد خاطره با فرآيند آفرينش مجدد الجاد رابط 


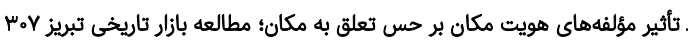

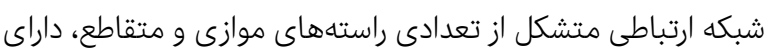

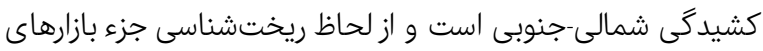

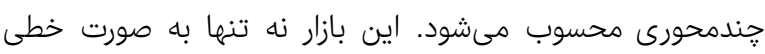

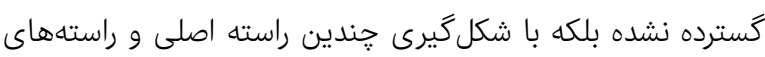

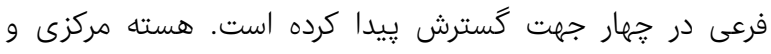

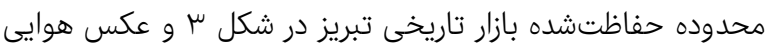

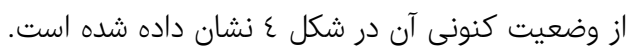

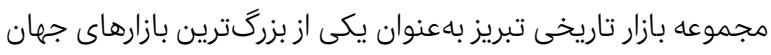

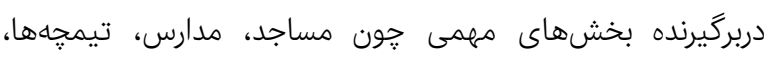

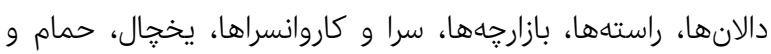

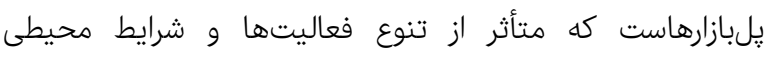

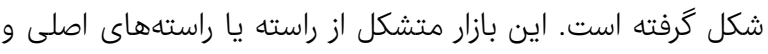

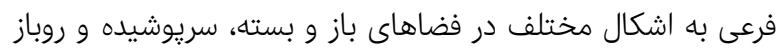
با طاقها و نورگيرها و كاربندىهاى زيبا است. تمام راستهها، بازارها،

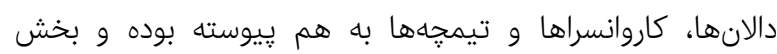

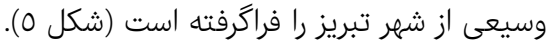
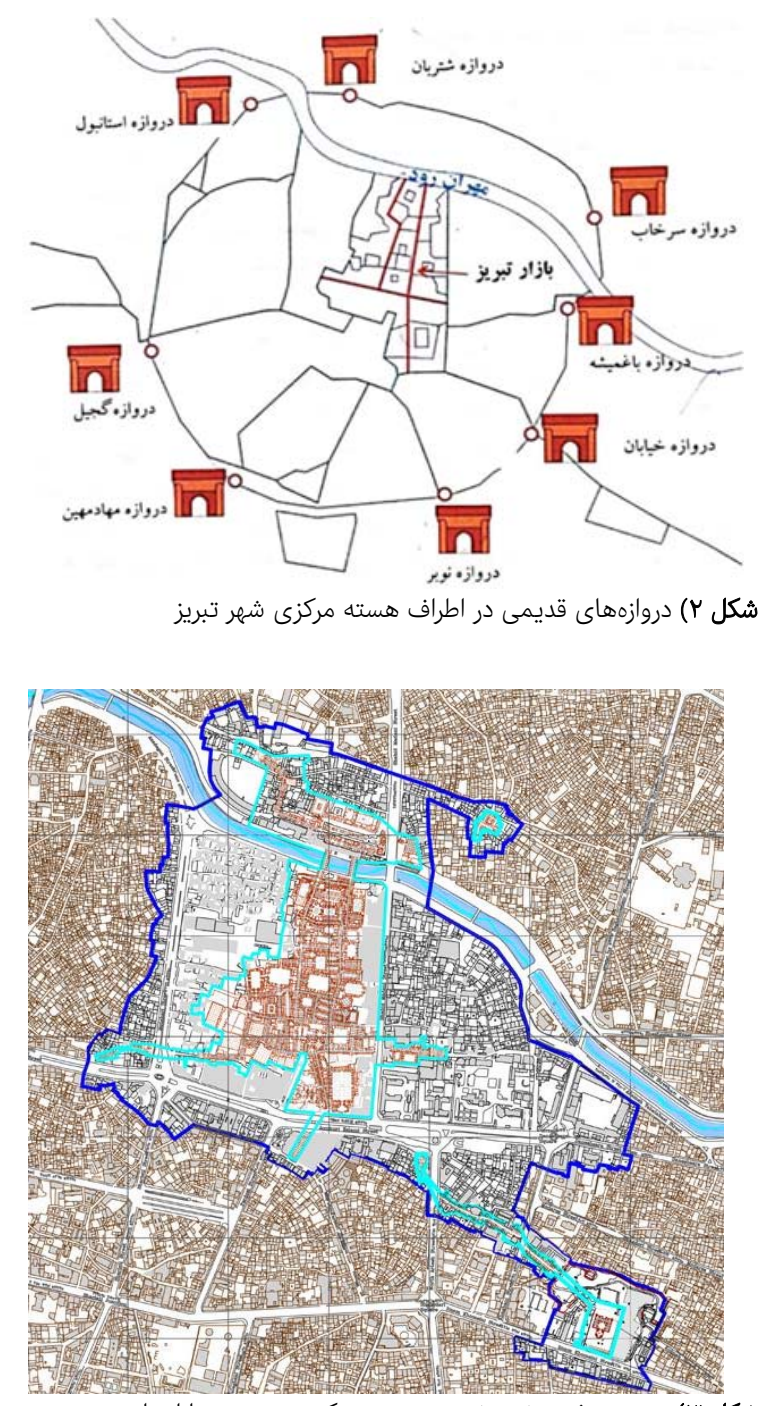

شكل س) محدوده ثبت شده شده و هسته مركزى محدوده بازار تاريخى تبريز [Iranian cultural heriage, handicrafts \& Turism Organization, 2008]

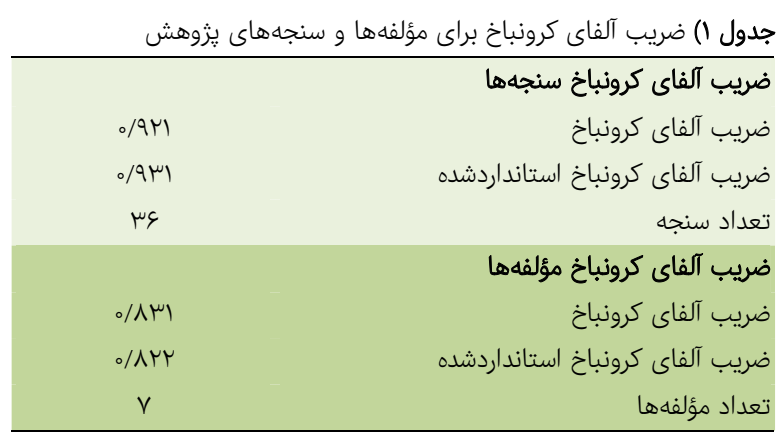

همجنين نمونه آمارى تحقيق بهوسيله فرمول كوكران با خطاى هاى

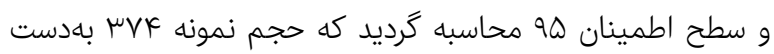

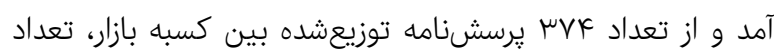

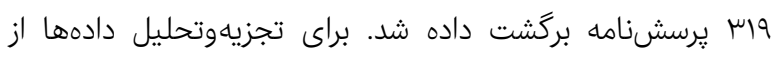

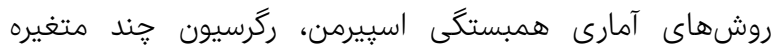
استفاده كرديد. بازار تاريخى تبريز به عنوان يكى از ارزندهترين بازارهاى ايرانى در

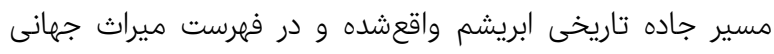

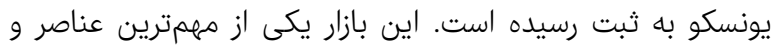

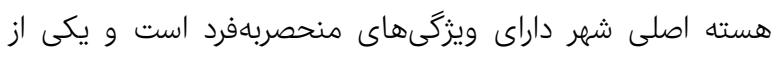

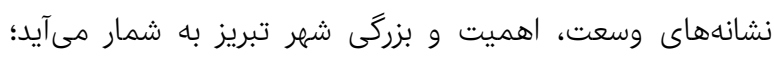

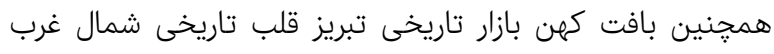

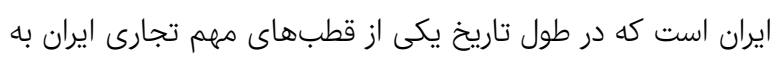

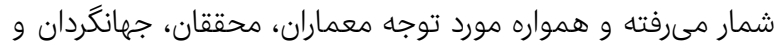

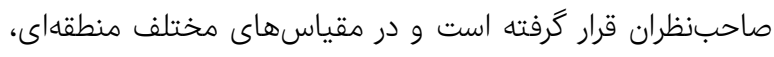

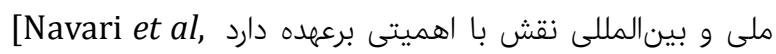
2008]

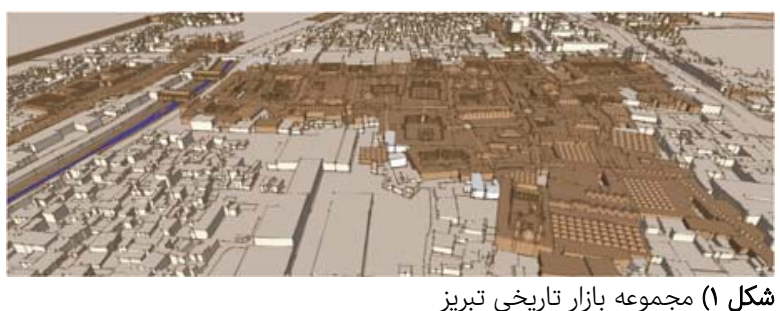

مجموعه شكوهمند بازار تاريخى تبريز در زلزله سال س111 هجرى إل

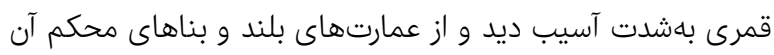

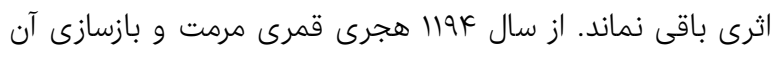

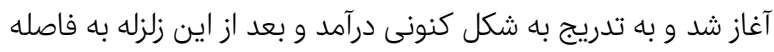

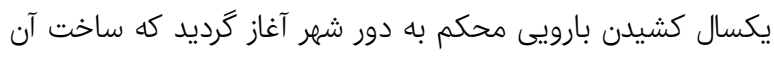

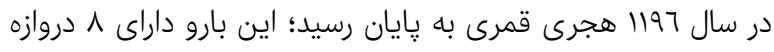

است [Habibi, 2014] (شكل r r).

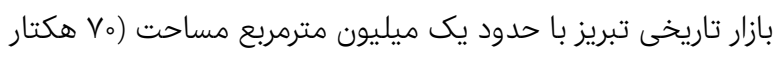

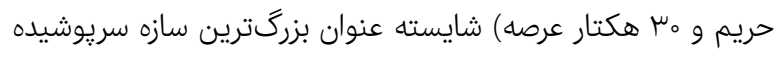

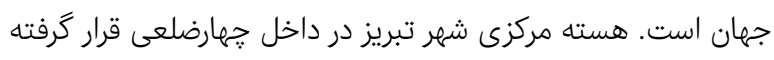

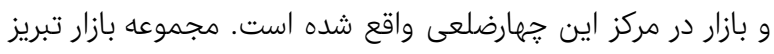


بازار تاريخى تبريز با دارابودن راستابازارها، سراها، تيمجهها، دالانها

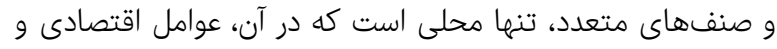

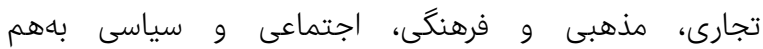

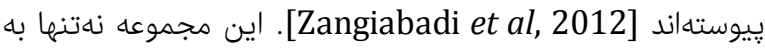
علت كارايى و عملكرد مطلوب، بلكه به دليل تبلور هويت تاريخى و

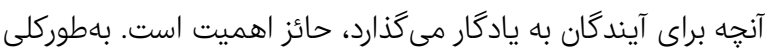
بازار تاريخى تبريز يكى از ساختارهاى هويتبخش شهرى بهرى وحافظ

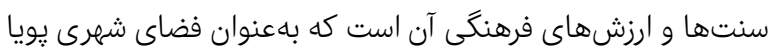

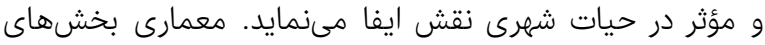

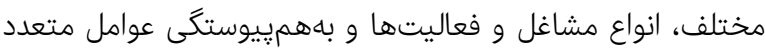

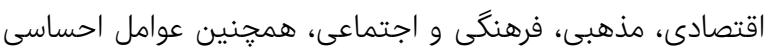

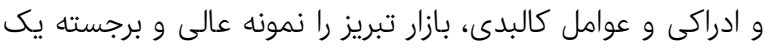
مكان تجارى، اجتماعى و معمارى نموده است.

يافتهها

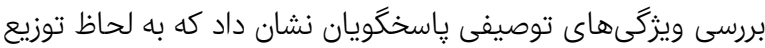

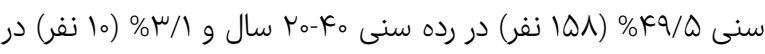

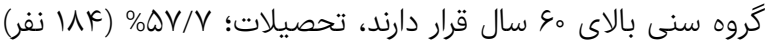
دييلم و زير دييلم، سابقه فعاليت؛

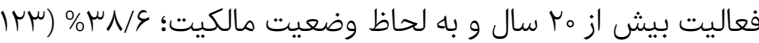

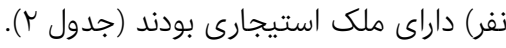

جدول r) فراوانى مطلق و نسبى ويزگىهاى جمعيتشناختى مشاركت كنندگان

\begin{tabular}{|c|c|c|}
\hline درصد & تعداد & شاخص \\
\hline & & توزيع سنى \\
\hline $1 / 9$ & $\varepsilon$ & كمتر از ro سال \\
\hline $\mathrm{kq} / \mathrm{Q}$ & $10 \Lambda$ & Kال Ko-ro \\
\hline$K Q / Q$ & $\| K \Delta$ & ( \\
\hline \multirow[t]{2}{*}{$\mu / \Lambda$} & 10 & بيشتر از هع سال \\
\hline & & سطح تحصيلات \\
\hline$\Delta \mathrm{V} / \mathrm{V}$ & lak & زير دييلم و دييلم \\
\hline $1 \pi / 9$ & $k 1$ & فوقدييلم \\
\hline$r_{0} / V$ & 98 & كارشناسى \\
\hline \multirow[t]{2}{*}{$\Lambda / \vee$} & ru & كارشناسى ارشد و بالاتر \\
\hline & & سابقه فعاليت \\
\hline $1 \pi / 0$ & $k_{0}$ & كمتر از ه سال \\
\hline$r_{0} / k$ & $\varepsilon \Delta$ & 1. - 0 سال \\
\hline MI/G & 99 & 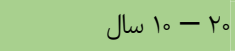 \\
\hline$k \Delta / Q$ & $\| \& \Delta$ & بيشتر از ro سال \\
\hline & & مالكيت \\
\hline$r \mu / \Lambda$ & Ve & 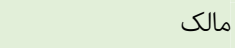 \\
\hline$\mu V / \varepsilon$ & $1 r_{0}$ & سرقفلى \\
\hline ץ// & Irr & استيجارى \\
\hline
\end{tabular}

همبستگى بين مؤلفههاى هويت مكانى بازار تاريخى تبريز

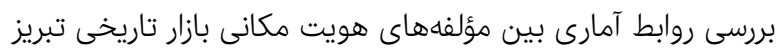

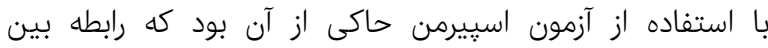

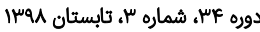

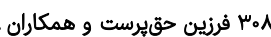

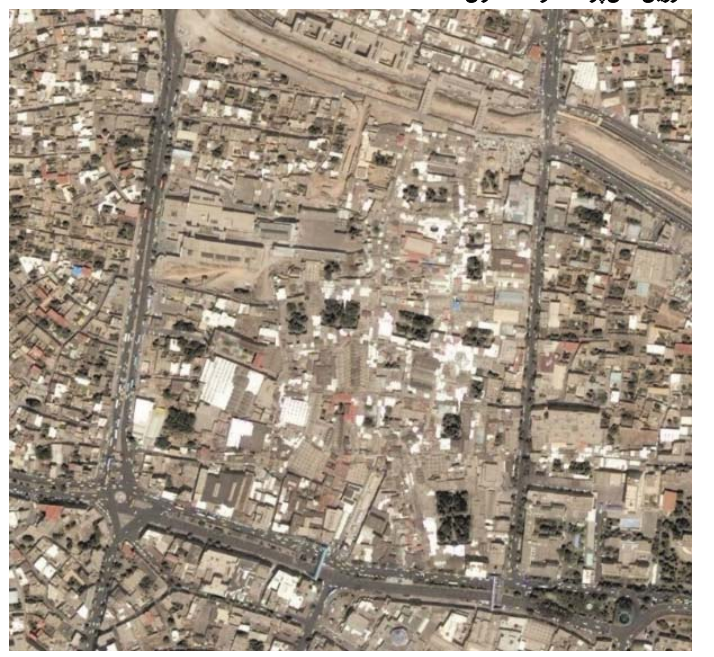

شكل \&) عكس هوايى از وضعيت كنونى بازار تاريخى تبريز [ICHHTO, 2009]

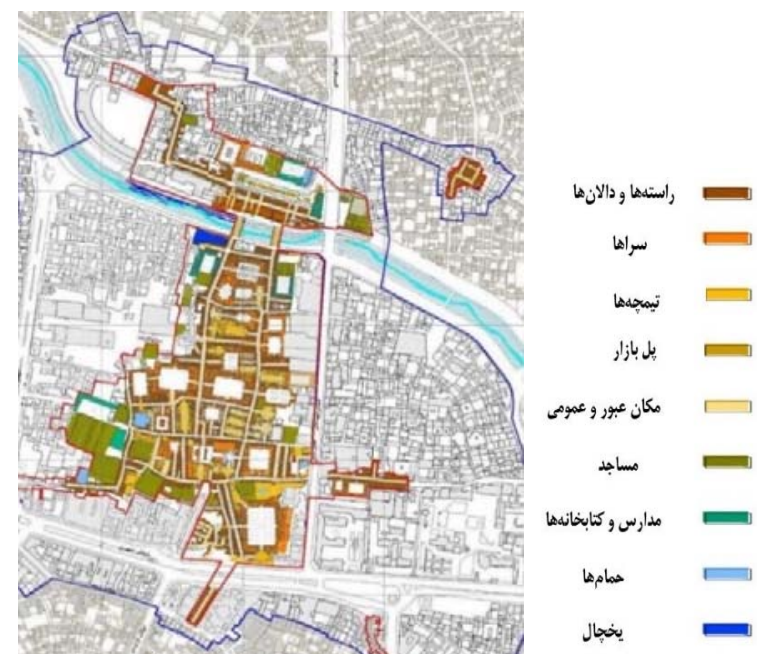

[ICHHTO, شكل ه) موقعيت عناصر و بخشهاى مختلف بازار تاريخى تبريز 2009]

اين مجموعه از سمت شمال، قسمتهايى از رودخانه مهرانرود را

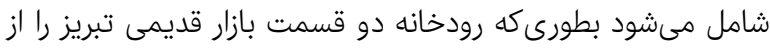
هم جدا نموده است. اين دو قسمت بلهوسيله يلهوداى قرارگرفته در برد امتداد راستهبازار به هم متصل شدهاند (شكل 7).

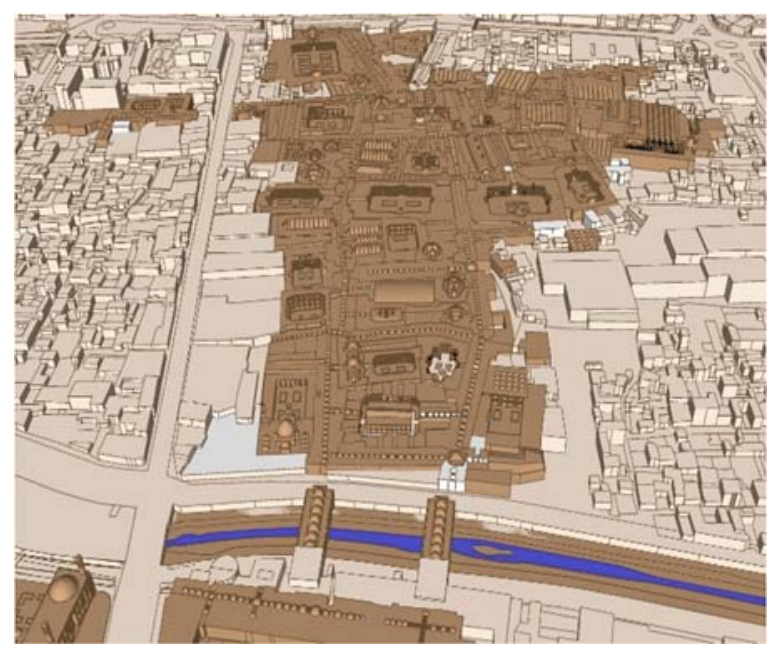

شكل 7) موقعيت مهرانرود و ارتباط آن با دو بخش بافت متراكم، پييوسته و منسجم بازار تاريخى تبريز فصلنامه تحقيقات جغرافيايى 


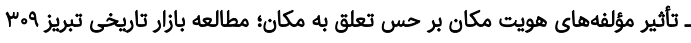

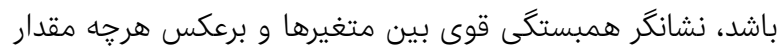

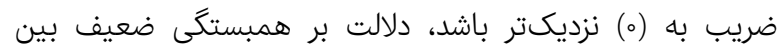

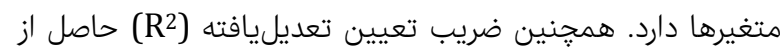

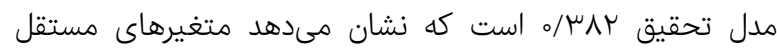

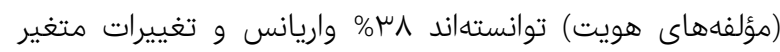

وابسته (حس تعلق مكانى) را تبيين كنند (جدول 0).

جدول ه) خلاصه آمارههاى برازش مدل رگرسيون

\begin{tabular}{|c|c|}
\hline.$/ 911$ & ضريب همبستكى حندكانه (R) \\
\hline o/rᄉr & مجذور ضريب همبستكى هندگانه (R²) \\
\hline$\circ / \mu V_{0}$ & ضريب تعيين تعديلشده (R²adj) \\
\hline$\circ / \Delta \mu_{0} \& \mu$ & خطاى استاندارد برآورد \\
\hline
\end{tabular}

همجنين جدول نتايج تحليل واريانس نيز نشان داد كه مقدار

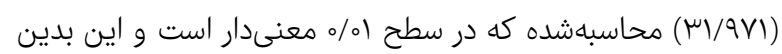
مفهوم است كه متغيرهاى مستقل تحقيق (مؤلفههاى هويت) از

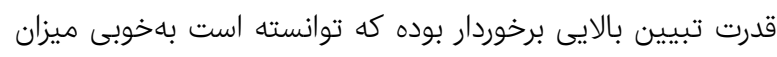

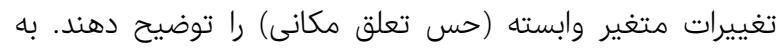
عبارتى مدل رگرسيونى تحقيق مدل مناسبى است كه به كمك آن

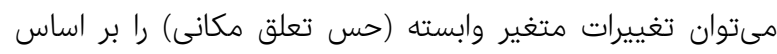
شش متغير مستقل تبيين نمود (جدول \&).

\begin{tabular}{|c|c|c|c|c|c|}
\hline \multicolumn{6}{|c|}{ جدول \&) نتايج تحليل واريانس } \\
\hline Sig & $\mathbf{F}$ & مجذانكين & درجه آزادى & مجذورات & مدل \\
\hline \multirow[t]{3}{*}{$\%$} & $\mu / / q V$ & Q/oor & $\varepsilon$ & $\Delta F / 0 I T$ & رخرسيون \\
\hline & & o/rAK & $\mu$ & $\Lambda V / T \wedge \Delta$ & باقىمانده \\
\hline & & & MIS & $|k| / T q V$ & كل \\
\hline
\end{tabular}

الف: ضريب رخرسيونى استانداردشده و استاندارد نشده

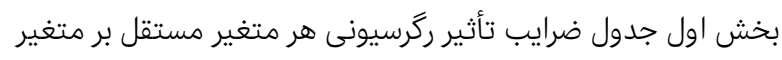

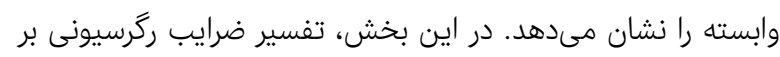

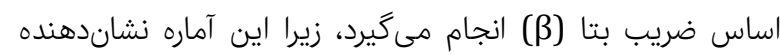

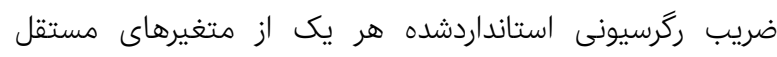

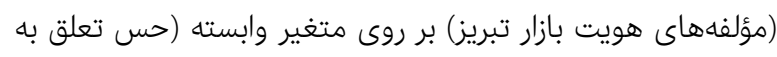

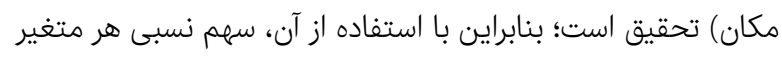

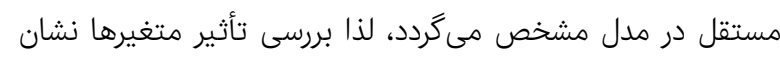

مى مهد: تأثير سه متغير خاطرهانكيزى، رضايتمندى، شناخت بر متغير حس تعلق به مكان، معنىدار بود؛ به دليل اينكه سطح خطاى آماره (t)

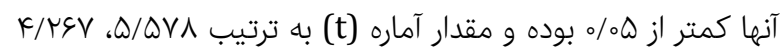

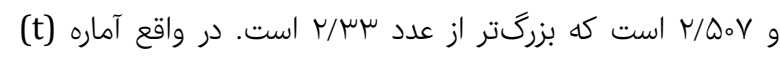

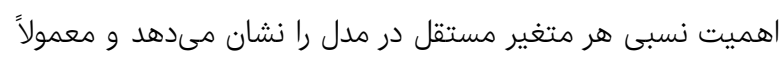

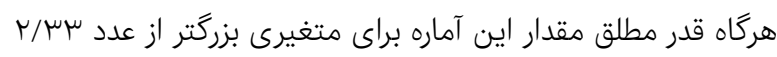

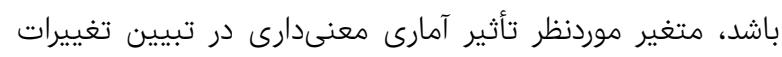

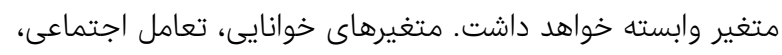

مؤلفه هاى شش گانه هويت در سطح p>0/p معنىدار است و ضرايب

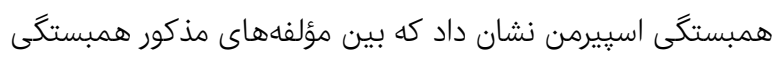

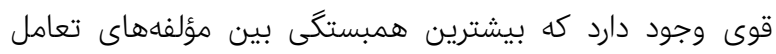

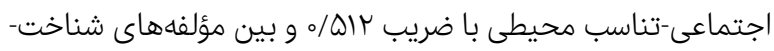

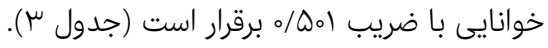
جدول سم) همبستخى بين مؤلفههاى هويت مكانى بازار تاريخى تبريز

\begin{tabular}{|c|c|c|c|c|c|c|}
\hline 8 & $\Delta$ & F & $\mu$ & $r$ & 1 & مؤلفه \\
\hline & & & & & 1 & شناخت (1) \\
\hline & & & & 1 & $\circ / \Delta .1$ & خوانايى (Y) \\
\hline & & & 1 & $\cdot / \mu \wedge \Lambda$ & ०/rqV & تناسب محيطى (س) \\
\hline & & 1 & o/DIT & $0 / k \varepsilon_{0}$ & $\circ / F \wedge 。$ & تعامل اجتماعى (F) \\
\hline & 1 & $. / k \mid r$ & $\circ / \mu \cdot \Delta$ & - $/ F F D$ & o/krg & خاطرهانكيزى (Q) \\
\hline 1 &.$/ 491$ &.$/$ rqk & o/FAY & $0 / 419$ & D & رضايتمندى (ع) \\
\hline
\end{tabular}

همبستگى بين مؤلفههاى هويت مكان و حس تعلق به مكانى بازار تبريز براى بررسى روابط آمارى بين مؤلفههاى هويت بازار تاريخى تبريز

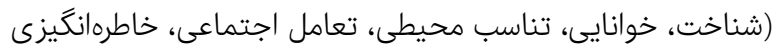

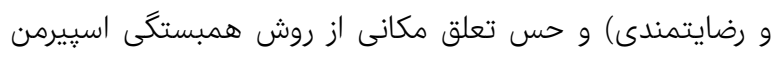

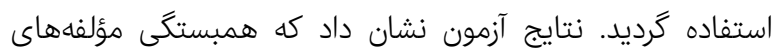

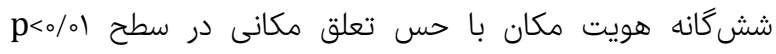

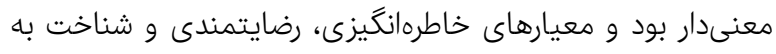

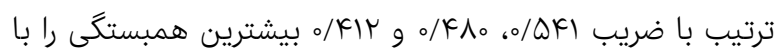
حس تعلق مكانى دارند (جدول \&).

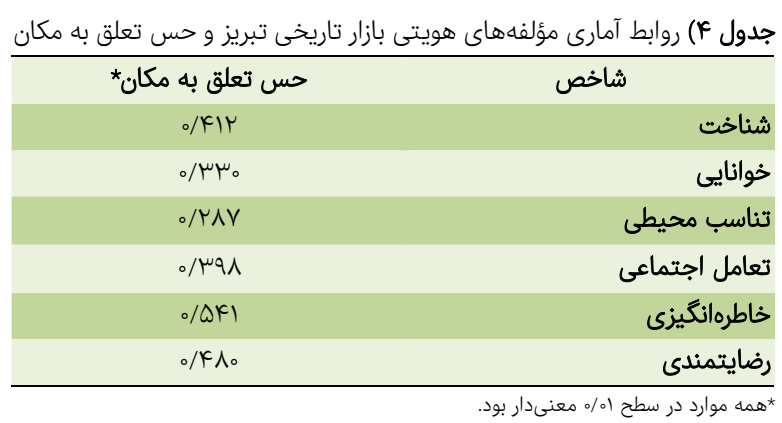

تحليل روابط على بين مؤلفههاى هويت مكانى و حس تعلق مكانى بازار تاريخى تبريز با توجه به اينكه يرسش اصلى تحقيق حاضر بررسى اين موضوع

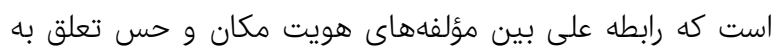

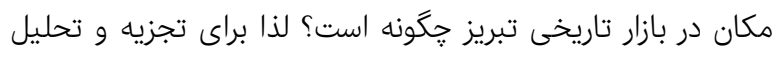

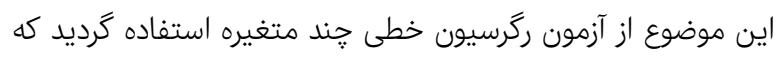

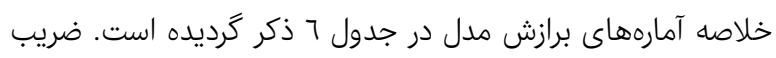

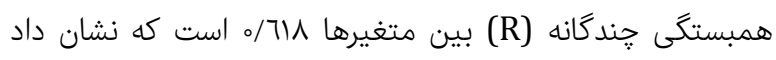
بين مجموعه متغيرهاى مستقل (مؤلفههاى هويت) و وابسته (حس (حسن

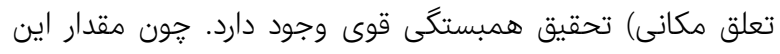

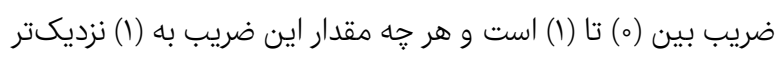


متغير وابسته را يس از حذف ميزان همبستكى اين دو متغير با

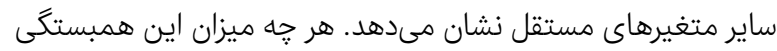
براى يك متغير بيشتر باشد، نقش آن متغير در مدل بيشتر مئر است.

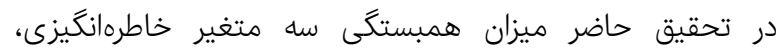

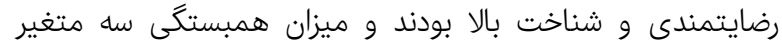

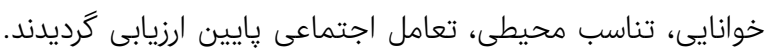

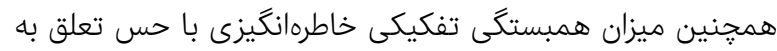

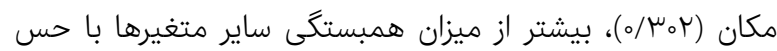
تعلق مكانى برآورد كَرديد.

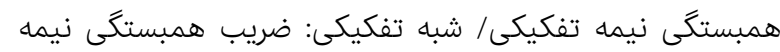

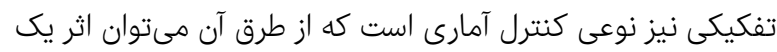

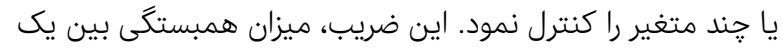

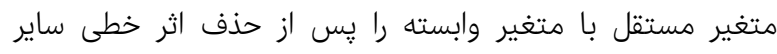
متغيرهاى مستقل بر متغير مستقل مورد نظر (و نه متغير وابسته)

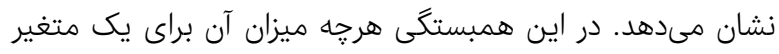

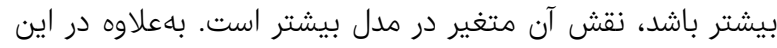

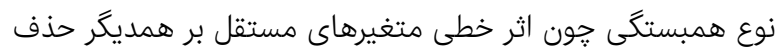

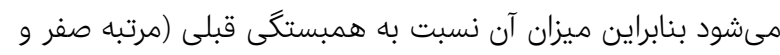

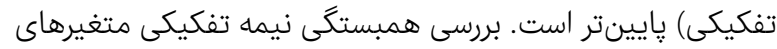

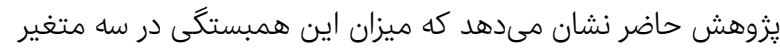

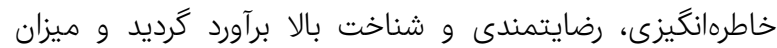

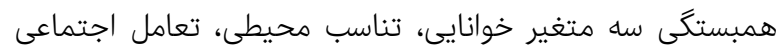

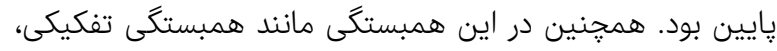

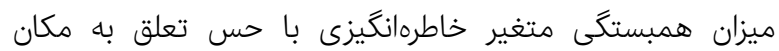

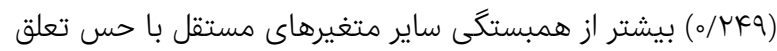

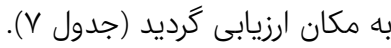

تناسب محيطى به خاطر اينكه سطح خطاى آماره (t) آنها بالاتر از

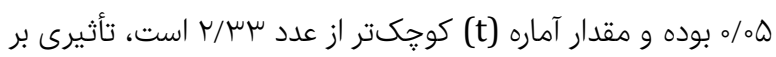
حس به تعلق مكان نداشته است. مارد ماره

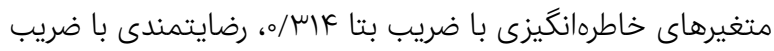

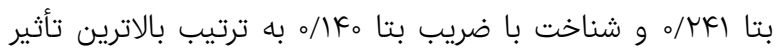

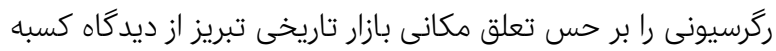

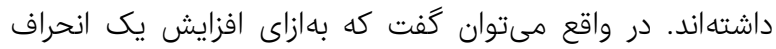

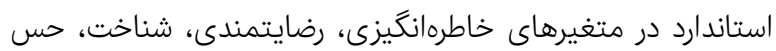

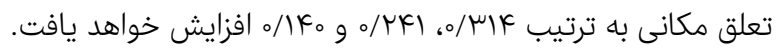

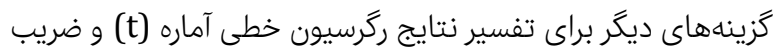

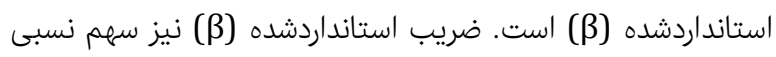
هر متغير مستقل را در تبيين تغييرات متغير وابسته مشخص

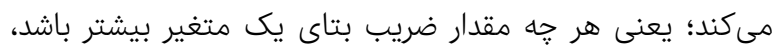

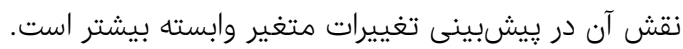

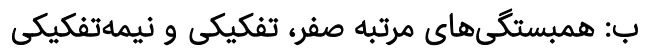

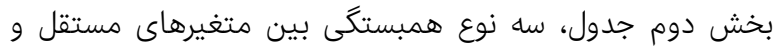

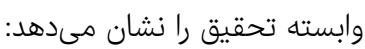

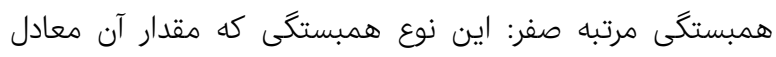

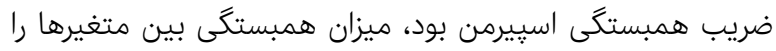

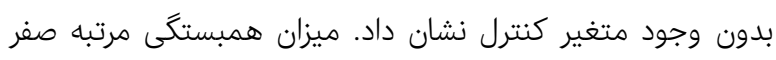

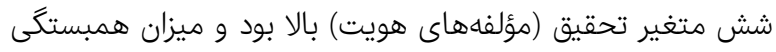

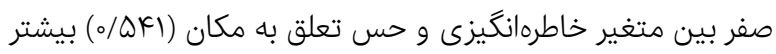
از ميزان همبستخى ساير متغيرهاى مستقل برآوردگرديد.

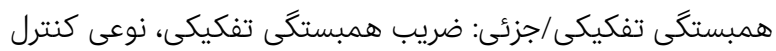

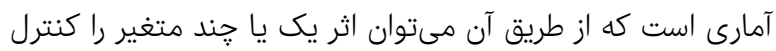

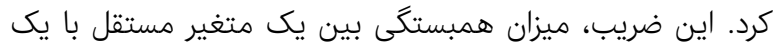

جدول V) نتايج مربوط به ميزان تأثير هر متغير در مدل و همجنين ميزان همبستخى بين آنها

\begin{tabular}{|c|c|c|c|c|c|c|c|c|}
\hline \multicolumn{3}{|c|}{ همبستكىها } & \multirow{2}{*}{ Sig } & \multirow{2}{*}{ t } & \multirow{2}{*}{ ضريب استاندارد نشده } & \multicolumn{2}{|c|}{ ضريب استاندارد نشده } & \multirow{2}{*}{ شاخص } \\
\hline نيمه تفكيكى & تفكيكى & مرتبه صفر & & & & خطاى استاندارد & B & \\
\hline & $\circ /|F|$ & o/kIr & \% & $r / \Delta . V$ & o/lk。 & \% \& & $\circ / \mathrm{QVV}$ & شناخت \\
\hline$\% \Delta \Delta F$ & $\circ \% 9 \wedge$ & 每/ & $\circ / \Gamma \mu$ 。 & $1 / T \circ k$ & $\% \& Y$ & $\% F V$ & $\% \Delta S$ & خوانايى \\
\hline$-0 \mu q$ & $-0 / 049$ & O/TAY & 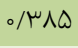 & $-0 / \wedge \& 9$ & $-0 / 0 k \lambda$ & $\% F Q$ & $-\circ / \%$ ४q & تناسب محيطى \\
\hline 1.94 & $\circ \vee \vee \wedge$ & $\circ / 491$ & o/199 & $1 / \mu \vee q$ & $\% / 11$ & $\% \Delta V Y$ & $\% \vee \wedge$ & تعامل اجتماعى \\
\hline $0 / r k q$ & $\circ / \mu \circ r$ & O/QKI & $\%$ & $\Delta / \Delta \vee \Lambda$ & o/MIK & $\% \vee \mu$ & $\circ / F_{0} D$ & خاطرهانكيزى \\
\hline$\circ / 19 \circ$ & عس & $0 / 4 \lambda_{0}$ & $\%$ & $K / T S V$ & $O / T K I$ & $\% F Q$ & $\circ / 191$ & رضايتمندى \\
\hline
\end{tabular}

حفاظت از آنها در اين يزوهش مورد تأكيد قرار گرفته است. توجه

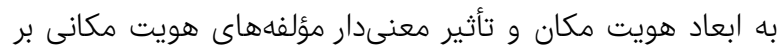
حس تعلق به مكان موجب هماهنكى افراد با مكان و رضايت از آن

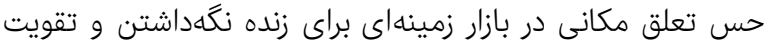

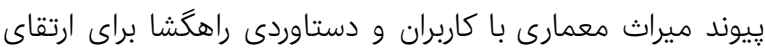

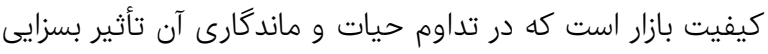
دارد. براين اساس مؤلفه شناخت، خوانايى، تناسب محيطى، تعامل

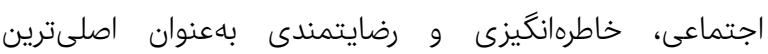

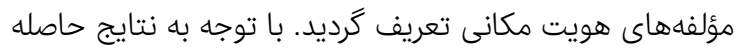

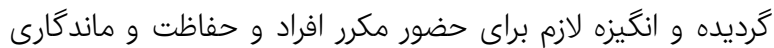

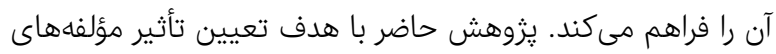

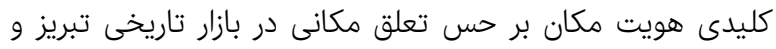

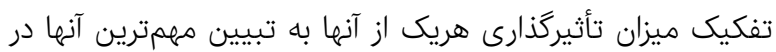
تقويت حس تعلق به مكان انجام بذيرفت. شناسايى شاخصتريك رئرين مؤلفههاى هويتى مؤثر بر حس تعلق به مكان به منظور توجه و 


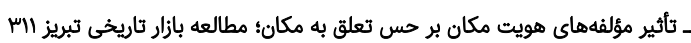

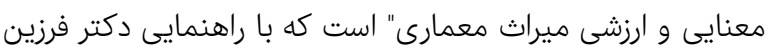

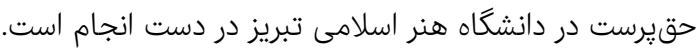

منابع

Abasi Z, Habib F, Mokhtabad Amraei M (2015). An analysis of environmental concepts affecting the meaning of component in the traditional Iranian market, case study: Comparative comparison of Kashan traditional market and safavid commercial complex of Kashan. Urban Management Quarterly. 14(40):159-176. [Persian]

Ahmadi F, Aghalatifi A, Afshar A (2014). Factors influencing a sense of belonging in the regeneration of noghan neighborhood in the residential fabric near the Imam Reza Shrine. Journal of the Urban Development and Organization Haft Shahr. 4(47-48):70-84. [Persian] Arbab P, Azizi MM, Zebardast ES (2016). Explanation of the key criteria of the process of Place-Identity formation in new urban development. Fine Arts Journal. 20(4):5-20. [Persian]

Low S, Altman I (1992). Place attachment. In: Altman I, Low SM, editors. Place Attachment. human behavior and environment (advances in theory and research), (Vol 12). Boston, MA: Springer.

Canter D (1977). The psychology of place (Vol 1). 1st ed. London: The Architectural Press Ltd.

Droseltis 0, Vignoles V (2010). Towards an integrative model of place identification: Dimensionality and predictors of intrapersonal-level place preferences. Journal of Environmental Psychology. 30(1):23-34.

Falahat MS (2006). Concept of sense of place and its constituent factors. Fine Arts Journal. 1(26):57-66. [Persian]

Giddens A (1991). Modernity and self - Identity: Self and society in the late modern age (Vol 1). 1st ed. Stanford: Stanford University Press.

Gustafson P (2001). Meaning of place: Very day experience and theorethical conceptualization. Journal of Environmental Psychology. 21(1):5-16

Habibi D, Habibi D, Kasalaei A, Gorjipoor F, Tavakoli M (2018). Explaining the sense of belonging to place and identity in urban spaces with an emphasis on traditional markets. Architecture. 1(3):1-8. [Persian]

Habibi H (2014). Tabriz Grand Bazaar. 1'st ed. Tehran: Bonyad-e Iran Shenasi. [Persian]

Heidari AA, Motalebi G, Negin Taji F (2014). Analysis of the physical sense of place in the traditional houses and modern residential apartments. Fine Arts Journal. 19(3):75-86. [Persian]

ICHHTO (2009). Executive summary Tabriz historical bazaar complex. $1^{\text {st }}$ ed. Geneve: UNESCO.

Javan Foruzandeh A, Motallebi G (2011). The concept of place attachment and its elements. HOVIATSHAHR. 5(8):27-37. [Persian]

Kalali P, Modiri A (2012). Explanation of the role of meaning component in the process of creating the sense of place. Fine Arts Journal. 17(2):43-52. [Persian]

Kashi H, Bonyadi N (2013). Stating the model of identity of place-sense of place and surveying its constituents case study: Pedestrian passage of Shahre Rey. Fine Arts Journal. 18(3):43-52. [Persian]

Mohammad Moradi A, Bahmani Oskooei F (2010). Traditional market: Crisising contemporary urbanism. Designer Quarterly. (2):131-138. [Persian]
همبستگى مهمترين مؤلفههاى هويت مكان با حس تعلق مكانى

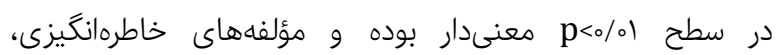

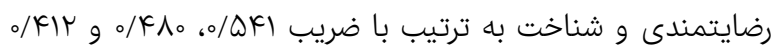

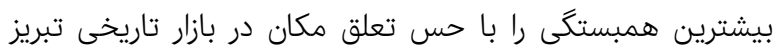

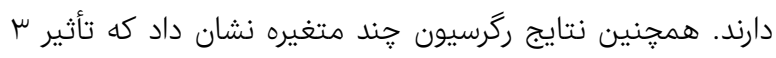

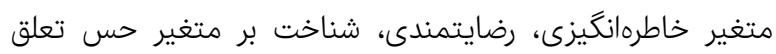
مكانى، معنىدار است به دليل اينكه سطح خطاى آماره (t) آنها

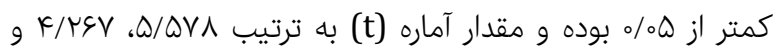
خاست r/D.V

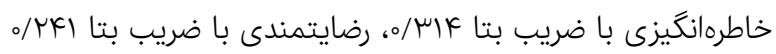

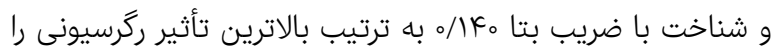

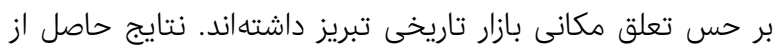

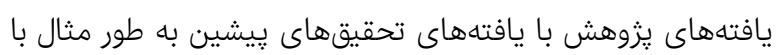

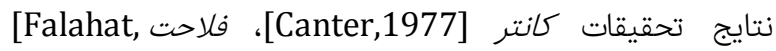

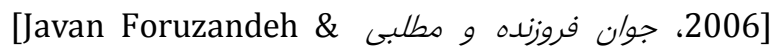
[Ahmadi et al, (Motallebi, 2011 [2014، حبيبى و همكاران [Habibi et al, 2018]، تان و همكاران [Tan, 2018] همخوانى دارد. نكته قابل توجه در اين

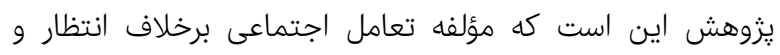

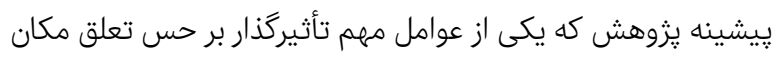

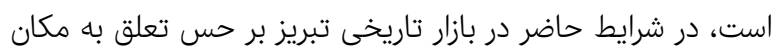

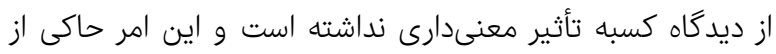

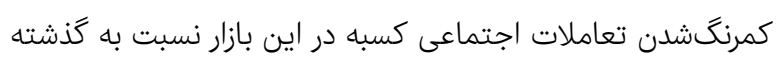
شده است كه بايستى مورد توجه جدى تراملى اجتمار كيرد.

نتيجه گيرى آكاهى از ماهيت و ميزان تأثير مؤلفههاى كليدى هويت مكانى بر

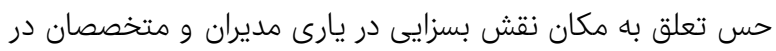

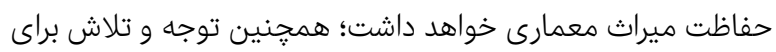

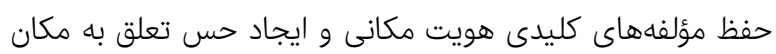

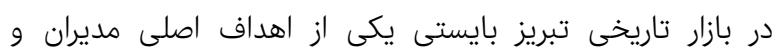

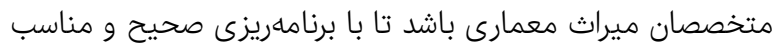

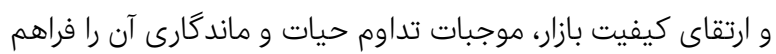
آورند.

$$
\begin{aligned}
& \text { تشكر و قدردانى: موردى از سوى نويسندكان كزارش نشده است. }
\end{aligned}
$$

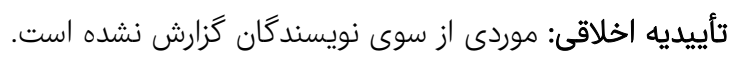

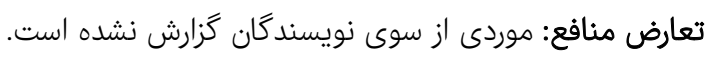

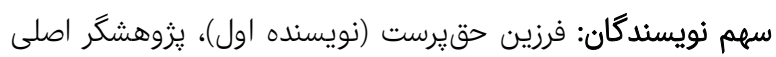

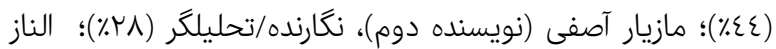

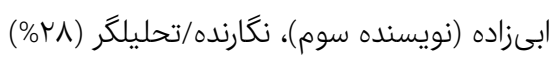

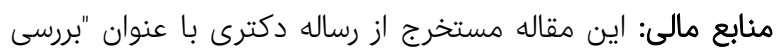

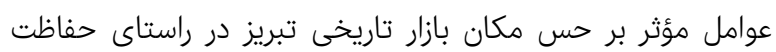


Tan S, Tan S, Kok Y, Choon Sh (2018). Sense of place and sustainability of intangible cultural heritage-The case of George Town and Melaka. Tourism Management. 67:376387.

Tavakolianferdosieh $\quad$ M, Esmaeelpuor $\quad \mathrm{N}$ Noghsanmohammadi M (2016). Redesigning bazaar based on its collective memories formation and retention case study: Bazaar Khan, city of Yazd. Bagh-e Nazar. 13(39):45-56. [Persian]

Tuan Y (1974). Classics in human geography revisited: Topophilia. Englewood Cliffs, NJ: Prentice-Hall. 18(3):355-359.

Zangiabadi A, Alizadeh J, Ranjbarnia B (2012). Strategic planning, to organize traditional Iranian markets a case study: The traditional market of Tabriz. Journal of Islamic Iranian Studies. 2(7):13-26. [Persian] Navari N, Khalilzade S, Fakhari Tehrani F (2008). Tabriz Markets Bridge. Sofeh Journal. 46(17):101-108. [Persian] Proshansky H (1978).The city and self-Identity. Environment and Behavior. 10(2):147-169.

Proshansky H, Fabian K, Kaminoff R (1983). PlaceIdentity: Physical world socialization of the self. Journal of Environmental Psychology. 3(1):57-83.

Relph E (2008). Place and placelessness. London: Sage; pp. 43-51.

Shamai S (1991). Sense of place: An empirical measurement. Geoforum. 22(3):347-358.

Soini K, Vaarala H, Pouta E (2012). Residents' sense of place and landscape perceptions at the rural-urban interface. Landscape and Urban Planning. 104(1):124-134.

Steele F (1981). The sense of place. $1^{\text {st }}$ ed. Boston, Mass: CBI Publishing Company. 